\title{
Applied tracers for the observation of subsurface stormflow at the hillslope scale
}

\author{
J. Wienhöfer ${ }^{1,2}$, K. Germer ${ }^{3}$, F. Lindenmaier ${ }^{1}$, A. Färber ${ }^{3}$, and E. Zehe ${ }^{1}$ \\ ${ }^{1}$ Institute of Water and Environment, Technische Universität München, München, Germany \\ ${ }^{2}$ Institute of Geoecology, University of Potsdam, Potsdam, Germany \\ ${ }^{3}$ Institute of Hydraulic Engineering, Universität Stuttgart, Stuttgart, Germany
}

Received: 8 March 2009 - Published in Hydrol. Earth Syst. Sci. Discuss.: 1 April 2009

Revised: 17 June 2009 - Accepted: 7 July 2009 - Published: 14 July 2009

\begin{abstract}
Rainfall-runoff response in temperate humid headwater catchments is mainly controlled by hydrological processes at the hillslope scale. Applied tracer experiments with fluorescent dye and salt tracers are well known tools in groundwater studies at the large scale and vadose zone studies at the plot scale, where they provide a means to characterise subsurface flow. We extend this approach to the hillslope scale to investigate saturated and unsaturated flow paths concertedly at a forested hillslope in the Austrian Alps. Dye staining experiments at the plot scale revealed that cracks and soil pipes function as preferential flow paths in the fine-textured soils of the study area, and these preferential flow structures were active in fast subsurface transport of tracers at the hillslope scale. Breakthrough curves obtained under steady flow conditions could be fitted well to a one-dimensional convection-dispersion model. Under natural rainfall a positive correlation of tracer concentrations to the transient flows was observed. The results of this study demonstrate qualitative and quantitative effects of preferential flow features on subsurface stormflow in a temperate humid headwater catchment. It turns out that, at the hillslope scale, the interactions of structures and processes are intrinsically complex, which implies that attempts to model such a hillslope satisfactorily require detailed investigations of effective structures and parameters at the scale of interest.
\end{abstract}

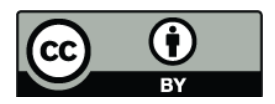

Correspondence to: J. Wienhöfer (j.wienhoefer@bv.tu-muenchen.de)

\section{Introduction}

Understanding hydrological processes and runoff generation is of prime importance for hydrological predictions. Hillslopes act in many landscapes as "filters" for water to enter the stream or the deeper subsurface. Rainfall-runoff processes at this scale are intrinsically complex (Bonell, 1993; Williams et al., 2002). Hillslope geometry, soil and bedrock properties, the vegetation pattern, and rainfall characteristics crucially determine time scales and processes of rainfallrunoff response. Subsurface stormflow (SSF) dominates the runoff response especially at steep hillslopes under wet conditions and intense rainfall. Subsurface stormflow is a generic term for rapid lateral flow processes in preferential flow paths with much higher flow velocities than in the surrounding soil matrix. These flow paths can be highly permeable saturated layers, fractured bedrock, soil pipes and macropores generated by biological activity, or pipes and cracks formed by soil physical processes (see Weiler et al., 2006, and references cited therein). Numerous studies have been dedicated to the conceptual understanding of SSF formation and the role of subsurface flow paths (Jones and Connelly, 2002; Kienzler and Naef, 2008b; McDonnell, 1990; Scherrer and Naef, 2003; Scherrer et al., 2007; Sidle et al., 2000; Tromp-van Meerveld et al., 2007; Tsuboyama et al., 1994; Uchida et al., 2004). Although conceptualisation and parameterisation of these processes still remain a great challenge (Uchida et al., 2006; Weiler and McDonnell, 2007), the importance of subsurface storm flow for runoff generation in headwater catchments is widely discussed and accepted (Jones and Connelly, 2002; Pearce et al., 1986; Scherrer et al., 2007; Uchida et al., 2002). 
Fast subsurface flow processes may, however, also influence the stability of hillslopes (Pierson, 1983; Uchida et al., 2001), especially in Alpine headwaters as recently suggested by Lindenmaier et al. (2005) for the Heumöser hillslope in Vorarlberg/Austria. In their study they related strong fluctuations in subsurface pressure heads in the lower hillslope sector to fast reactions of a spring that feeds from the steep south western part of the Heumöser. The buoyancy caused by these fluctuations was deemed to be a major driver of the observed slope movement. The rationale behind the research presented here was to investigate in further detail the processes and structures that cause these fast reactions in spring discharge, which is important for understanding the mechanisms underlying the movement of the Heumöser slope and thus is fundamental for mitigating the risk of slope failure.

\subsection{Tracer tests}

Natural and artificial tracers are powerful tools for investigating subsurface flow processes and flow paths both in the saturated as well as in the vadose zone. They can yield information integrated over large control volumes, including the effects of subsurface heterogeneities. The obtained patterns and breakthrough curves are thus a reflection of the effective subsurface structures. The selection of the appropriate tracers for a specific problem depends on the investigated system and the spatial and temporal scales of interest.

For the investigation of SSF natural tracers such as environmental isotopes and geochemical constituents are widely used. They allow hydrograph separation into event water and pre-event water and determination of transit time distributions at the catchment scale (e.g. Kirchner et al., 2001; McGuire and McDonnell, 2006; Uhlenbrook et al., 2002). However, the method requires sampling and expensive measurement equipment, and the combination with controlled sprinkling experiments is difficult to establish.

Applied tracers, especially dye tracers, have been used in streamwater and groundwater hydrology for over a 100 years (Käss, 1998). Obvious advantages of dyes are - in certain concentration ranges - their visibility and their low detection limit in the case of fluorescent dyes. Furthermore, time series of fluorescence tracer concentrations may be obtained in situ with high temporal resolution by field fluorimetry. However, dyes are generally non-conservative and partly highly absorptive (Kasnavia et al., 1999). The main objectives of dye tracer experiments are investigation of hydraulic connections and flow pathways, determination of aquifer recharge and stream discharge, or analysing flow velocities and dispersivities to assess aquifer properties; cf. recent reviews by Ptak et al. (2004), Divine and McDonnell (2005) and Flury and Wai (2003). In the past few decades dyes have also been used to evaluate subsurface flow in the vadose zone, ranging from plot (Mosley, 1979; Omoti and Wild, 1979b; Mikovari et al., 1995) to hillslope scale (Joerin et al., 2005; Kienzler and Naef, 2008a; Stamm et al., 2002). Since Flury et al.
(1994) dye staining techniques have become popular to visualise preferential flow pathways in excavated soil profiles at the plot scale (e.g. Blume et al., 2008; Weiler and Naef, 2003; Zehe and Flühler, 2001a), and also at the hillslope scale (Anderson et al., 2009; Noguchi et al., 1999). The advantage of dye staining experiments is that flow patterns can be obtained in high spatial resolution by image analysis. The major drawback of the method is that it is inherently invasive and destructive and thus limited in its applicability.

Besides dyes, inorganic halogen compounds, especially bromide and chloride species, have been established to investigate flow and leaching processes in the vadose zone in soil column experiments (e.g. Binley et al., 1996; Jensen et al., 1996; Henderson et al., 1996), at the plot or lysimeter scale (e.g. Hornberger et al., 1990; Tsuboyama et al., 1994; Deeks et al., 2008) and at the field or hillslope scale (e.g. Roth et al., 1991; Lange et al., 1996; Zehe and Flühler, 2001b). Advantages of these salt tracers (e.g. $\mathrm{NaCl}$ or $\mathrm{NaBr}$ ) are that they are non-sorptive and conservative. In contrast, their specific determination involves laborious sampling procedures and chromatography to obtain accurate concentrations.

\subsection{Outline of the paper: approach and objectives}

This study comprises experimental work with different artificial tracers at different scales. At the hillslope scale, we employed fluorescent dyes and conservative salt tracers together with rainfall simulation experiments in order to investigate the hydrological functioning of the hillslope under quasi-steady state conditions and under transient (natural) rainfall conditions based on continuous concentration time series. To better understand the transport of these tracers in the specific soil material, we performed similar tracer tests on an undisturbed soil block from the studied hillslope. At the plot scale, we performed dye staining experiments using Brilliant Blue FCF to explore occurrence and type of subsurface flow paths.

The major objective of this study is to qualitatively and quantitatively assess possible subsurface flow paths and their functional role in hydraulic processes under heavy rainfall conditions. The experimental work aims at a better understanding of the processes and structures that are causing the fast reactions in spring discharge in the south west part of the study area Heumöser, which is deemed to be a critical source area for the slope movement. A specific objective is to test a lumped-parameter approach for an effective description of the system. A methodological objective is to test the feasibility of applied tracer tests associated with rainfall simulation in a steep forested environment with cohesive soils, with particular emphasis on the applicability of fluorescent dye tracers and in situ fluorimetry to investigate the interactions of the unsaturated and saturated zone processes. Before we describe the experimental setup, the employed tracers and the methods to analyse the tracer data in detail, we give a short description of the study site. 


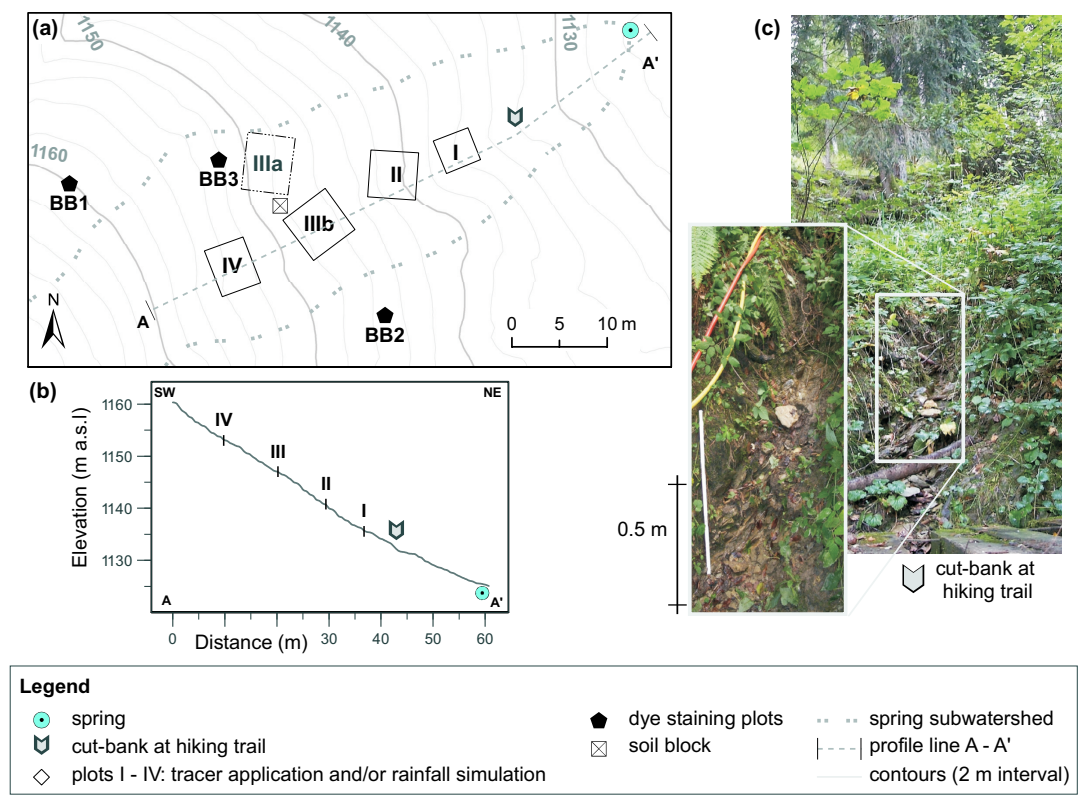

Fig. 1. (a) Map of experimental area and setup of hillslope tracer experiments. (b) Topographic cross section along A-A' in inset (a). (c) Photographs of cut-bank where a hiking trail crosses the slope and exfiltration occurs after rainfall events. Fluorescence tracers were measured in the outflow at this location and at the spring.

\section{Materials and methods}

\subsection{Study area}

The study area Heumöser is located in the Vorarlberg Alps (Austria), $10 \mathrm{~km}$ south-east of the city of Dornbirn and $0.5 \mathrm{~km}$ south of the village of Ebnit $\left(47^{\circ} 21^{\prime} 0.2^{\prime \prime} \mathrm{N}\right.$, $\left.9^{\circ} 44^{\prime} 46.6^{\prime \prime} \mathrm{E}\right)$. A short overview is given here; further details on the site are given by Lindenmaier et al. (2005), Lindenmaier (2008) and Wienhöfer et al. (2009). The extension of the slope is $1800 \mathrm{~m}$ in east-west and about $500 \mathrm{~m}$ in a north-south direction and the elevation ranges from 940 to $1360 \mathrm{~m}$ a.s.1. The Heumöser belongs to the head of a steep mountainous catchment which is drained by the Ebniterach/Dornbirnerach. The long-term average annual precipitation depth is $2155 \mathrm{~mm}$. The summer months (April to September) are the wetter season of the year, with average monthly rainfall depths between 160 and $250 \mathrm{~mm}$ and intensities of up to $12 \mathrm{~mm}$ in $10 \mathrm{~min}$. The most extreme storm in the 100 year record occurred on 22-23 August 2005 and delivered $248.2 \mathrm{~mm}$ of rainfall in $37.7 \mathrm{~h}$ (Lindenmaier, 2008). Mean annual temperature is around $7^{\circ} \mathrm{C}$ and annual evapotranspiration accumulates to $500-600 \mathrm{~mm}$.

This study is focused on the source area of a spring (Fig. 1) in the south-western part of Heumöser slope, which shows both perennial discharge and fast reactions to rainfall and is considered a source area of subsurface flow processes that trigger slope movement. It is a subcatchment of approximately $1000 \mathrm{~m}^{2}$ delimited by two small ridges on the steep side slopes of the catchment, where vegetation is dominated by common spruce (Picea abies) and sycamore maple (Acer pseudoplatanus). Slope angles vary between 18 and $54^{\circ}$ (median: $30^{\circ}$ ). Spring discharge is recorded in intervals of $10 \mathrm{~min}$ (water stage recorder: ATP15 Beaver, AquiTronic Umweltmesstechnik GmbH, Kirchheim/Teck, Germany) and ranges from 0.02 to $0.331 \mathrm{~s}^{-1}$. The spring shows short response times to rainfall (Lindenmaier, 2008), and at the same time spring discharge is perennial, which suggests that base flow is possibly sustained by a bedrock aquifer. The bedrock is built up by upper cretaceous sediments, mainly marls and limy marls. Soils are siltic and vertic Cambisols in the midslope, and stagnic and gleyic Cambisols and Gleysols at the hillslope toe. Soil depths vary between $0.35 \mathrm{~m}$ to $>1.00 \mathrm{~m}$ (median $0.74 \mathrm{~m}$ ); soil depth appears to be controlled by microrelief rather than by position along the slope line. Porosities in the topsoil $(0-10 \mathrm{~cm})$ are high $(0.48-0.73$, median 0.58$)$ with low bulk densities $\left(0.5-1.1 \mathrm{~g} \mathrm{~cm}^{-1}\right.$, median $\left.0.63 \mathrm{~g} \mathrm{~cm}^{-1}\right)$, soil texture is sandy loam. Below a depth of $10 \mathrm{~cm}$ soil textures are significantly finer and classified as silt loam and silty clay loam. In situ measurements using a compact constant head permeameter (Amoozegar, 1989) indicate a decrease in saturated hydraulic conductivity with depth, from median values of $2.5 \times 10^{-5} \mathrm{~m} \mathrm{~s}^{-1}$ in $12.5 \mathrm{~cm}$ and $1.3 \times 10^{-5} \mathrm{~m} \mathrm{~s}^{-1}$ in $19-25 \mathrm{~cm}$, respectively, to the range of $10^{-6}$ to $10^{-7} \mathrm{~m} \mathrm{~s}^{-1}$ in $30-100 \mathrm{~cm}$ depth (Wienhöfer et al., 2009). At one-fifth of the measurement locations $(n=41)$, regardless of measurement depth, the device's maximum measurable outflow rate of approximately $1 \times 10^{-4} \mathrm{~m} \mathrm{~s}^{-1}$ (Sobieraj et al., 2004) was exceeded due to fast flow because of macropores. 
Table 1. Details of tracer experiments at the hillslope scale and with the soil block.

\begin{tabular}{lrr}
\hline $\begin{array}{l}\text { Experiment identifier and } \\
\text { employed tracers }\end{array}$ & $\begin{array}{r}\text { Location of application } \\
\text { (application area/total plot area) }\end{array}$ & $\begin{array}{r}\text { Applied tracer mass, } \\
\text { volume of solution }\end{array}$ \\
\hline $\begin{array}{l}\text { Soil block } \\
\text { Uranine } 1\end{array}$ & & $0.4 \mathrm{~g}$ in 0.11 \\
Uranine 2 & Soil block $\left(0.0506 \mathrm{~m}^{2}\right)$ & $0.25 \mathrm{~g}$ in 0.11 \\
Salt $1: \mathrm{NaCl}$ & & $5 \mathrm{~g}$ in 0.11 \\
Salt 2: $\mathrm{NaCl}$ & & $5 \mathrm{~g}$ in 0.11 \\
Hillslope scale: Natural rainfall & Plot IV $\left(4 \mathrm{~m}^{2} / 20 \mathrm{~m}^{2}\right)$ & $2.1 \mathrm{~g} / 4.2 \mathrm{~g}$ in 4.51 \\
Uranine/ Sulforhodamine G & Plot IIIa $\left(0.24 \mathrm{~m}^{2}\right)$ & $3000.0 \mathrm{~g}$ in 101 \\
NaCl & Plot II $\left(4 \mathrm{~m}^{2} / 29 \mathrm{~m}^{2}\right)$ & $772.72 \mathrm{~g}$ in 101 \\
NaBr & Plot I $\left(9 \mathrm{~m}^{2} / 33 \mathrm{~m}^{2}\right)$ & $0.4 \mathrm{~g} / 0.8 \mathrm{~g}$ in 0.91 \\
Uranine/ Sulforhodamine G & & \\
Hillslope scale: steady-state & Plot IIIb $\left(4 \mathrm{~m}^{2} / 33 \mathrm{~m}^{2}\right)$ & $2.5 \mathrm{~g}$ in 2.51 \\
Uranine 1 & Plot IIIb $\left(4 \mathrm{~m}^{2} / 33 \mathrm{~m}^{2}\right)$ & $2.5 \mathrm{~g}$ in 2.51 \\
Uranine 2 & Plot I $\left(4 \mathrm{~m}^{2} / 15 \mathrm{~m}^{2}\right)$ & $2500.0 \mathrm{~g}$ in 151 \\
Salt $1: \mathrm{NaCl}$ & Plot II $\left(4 \mathrm{~m}^{2} / 28 \mathrm{~m}^{2}\right)$ & $2277.3 \mathrm{~g}$ in 151 \\
Salt 2: $\mathrm{NaCl}$ & &
\end{tabular}

\subsection{Fluorescent dye and salt tracers}

In the tracer experiments described in the following sections, the fluorescent dyes uranine (sodium fluorescein, CAS 51847-8, C.I. 45350) and sulforhodamine G (CAS 5873-16-5, C.I. 45220$)$ as well as the salt tracers sodium chloride $(\mathrm{NaCl}$, CAS 7647-14-5) and sodium bromide (NaBr, CAS 7647-15$6)$ were used. Each of the tracer experiments presented in this paper consisted of three phases: (1) pre-saturation, (2) tracer application, and (3) flushing with tracer-free water. Tracers were applied manually in solved form as pulse input onto the undisturbed soil surface from which only large pieces of litter were removed carefully by hand. Fluorescent dye tracer concentrations in the outflow were monitored in situ using fiber-optic fluorimeters (Mobiles LLF, Hermes Messtechnik, Stuttgart, Germany); for a description of the principle of fibre-optic fluorimetry see Ptak and Schmid (1996). Determination of salt concentrations was either done in situ with measurements of specific electrical conductivity, which were calibrated against salt concentrations, or with ion exchange chromatography on collected samples.

\subsection{Soil block laboratory experiments}

To quantify the interactions of fluorescence tracers and the soil material, an undisturbed soil block (surface area $0.25 \times 0.25 \mathrm{~m}$, depth $0.35 \mathrm{~m}$ ) was isolated next to plot IIIb after the hillslope tracer tests. The block was surrounded by a wooden box and the voids filled with gypsum (cf. Bouma and Dekker, 1981). The edges along the surface were additionally covered with gypsum to minimise boundary effects, resulting in an uncovered surface area of $0.22 \times 0.23 \mathrm{~m}$. Af- ter the gypsum dried up, the soil block was carefully cut off at the base and transported to the laboratory, where it was mounted on a perforated metal plate over a plastic funnel. Tap water delivered from a constant head tank was used for infiltration; rates were chosen such that the whole soil surface was covered by a water film while ponding on the irregular soil surface was $5 \mathrm{~mm}$ or less. The tracers uranine and $\mathrm{NaCl}$ were applied in two runs each; details of the tracer application are given in Table 1. Dye tracer concentrations in the outflow were measured with a fluorimeter in intervals of 10 to $60 \mathrm{~s}$. Salt tracer concentrations in the outflow were measured at one minute intervals using a hand-held conductivity-meter (Cond340i, WTW Wissenschaftlich-Technische Werkstätten $\mathrm{GmbH}$, Weilheim, Germany). The $\mathrm{pH}$ of the outflow was checked on selected samples taken during the experiment. Flow was interrupted for $19 \mathrm{~d}$ during the first uranine transport experiment to check for non-ideal transport behaviour (Brusseau et al., 1997).

\subsection{Hillslope tracer experiments}

Two sets of tracer experiments were conducted at the study site. Rainfall was simulated on four plots (total area: $106 \mathrm{~m}^{2}$ ) along the slope line (Fig. 1) with the use of oscillating sprinklers, as suggested by Zehe and Flühler (2001a). The sprinkling water was taken from a creek, approx. $100 \mathrm{~m}$ north of the spring. The sprinklers were fed from a storage container using two groundwater pumps (MP1, Grundfos, Bjerringbro, Denmark). The pumps and sprinklers were regulated to obtain a constant sprinkling rate of $12 \mathrm{~mm} \mathrm{~h}^{-1}$ on all four plots. Rates of applied and natural rainfall were checked using tipping-bucket rain gauges and rainfall collectors. 
Table 2. First hillslope tracer experiment - correlations of tracer BTCs, rainfall and spring discharge: Pearson product-moment correlation coefficients $r$ and time lags [s] for complete time series and periods during and after rainfall simulations, respectively. Time lags are positive if column variables are preceding.

\begin{tabular}{lcccccc}
\hline & $\begin{array}{c}\text { effective (natural }+ \\
\text { applied) rainfall }\end{array}$ & natural rainfall & spring discharge \\
\cline { 2 - 7 } & $r$ & time lag [s] & $r$ & time lag [s] & $r$ & time lag [s] \\
\hline $\begin{array}{l}\text { complete series } \\
\text { uranine }\end{array}$ & 0.49 & 2400 & 0.29 & 2520 & 0.43 & 120 \\
$\quad$ sulforhodamine G & 0.67 & 240 & 0.66 & 240 & 0.58 & -2400 \\
spring discharge & 0.24 & 2520 & 0.54 & 2640 & & \\
during simulation & & & & & & \\
$\quad$ uranine & 0.11 & 2400 & 0.00 & 2400 & -0.62 & 120 \\
$\quad$ sulforhodamine G & 0.43 & 240 & 0.33 & 240 & -0.05 & -2400 \\
$\quad$ spring discharge & 0.04 & 2520 & 0.70 & 5400 & & \\
after simulation & & & & & & \\
uranine & 0.37 & 2400 & 0.37 & 2400 & 0.64 & 120 \\
$\quad$ sulforhodamine G & 0.75 & 240 & 0.75 & 240 & 0.72 & -2400 \\
spring discharge & 0.55 & 2520 & 0.55 & 2520 & & \\
\hline
\end{tabular}

\subsubsection{First hillslope tracer experiment}

The dyes uranine and sulforhodamine $\mathrm{G}$ and the salt tracers sodium bromide $(\mathrm{NaBr})$ and sodium chloride $(\mathrm{NaCl})$ were used for this experiment in August 2006. Sodium chloride was applied as a pulse from a line source $(2.4 \times 0.1 \mathrm{~m}$, $0.2 \mathrm{~m}$ deep). The rest of the tracers were applied as a pulse onto the forest floor using a watering can. Tracers were applied subsequently on plots IV to I (cf. Table 1) at $10 \mathrm{~min}$ intervals. Sulforhodamine $\mathrm{G}$ concentrations were measured in the outflow from the cut-bank and uranine concentrations were measured in spring discharge; measurement intervals were $120 \mathrm{~s}$. Salt concentrations were determined with ion exchange chromatography in the laboratory on selected samples from the spring. Samples were taken with an automatic sampling device (6700 Portable Sampler, Teledyne Isco Inc., Lincoln, NE, USA) in increasing intervals of $10 \mathrm{~min}$ to $60 \mathrm{~min}$. Electrical conductivity and temperature were monitored at five-minute intervals at the spring (YSI 600 R, YSI Environmental, Yellow Springs, OH, USA).

\subsubsection{Second hillslope tracer experiment}

For this experiment in August 2007 the tracers uranine and sodium chloride were used. The tracers were applied as a pulse onto the forest floor using a watering can; the procedure was repeated for a second run of the experiment (for details on tracer application see Table 1). Uranine concentrations were measured in the outflow from the cut-bank near the hiking trail and in spring discharge at intervals of $10 \mathrm{~s}$. At the cut-bank, a Thompson weir with a pressure transducer was installed to quantify discharge for the du- ration of this experiment. Electrical conductivity and temperature of the outflow were recorded at one-minute intervals using a hand-held conductivity-meter (Cond340i, WTW Wissenschaftlich-Technische Werkstätten GmbH, Weilheim, Germany). At the spring, a conductivity-meter (YSI 600 R, YSI Environmental, Yellow Springs, OH, USA) was used to record electrical conductivity and temperature of spring water at five-minute intervals.

\subsection{Dye staining experiments}

To qualitatively assess possible flow paths on the hillslope, we conducted three staining dye tracer experiments using Brilliant Blue FCF (CAS [3844-45-9], C.I. 42090). The location of the plots BB1-BB3 are shown in Fig. 1. Volumetric soil moisture was determined next to the plots $\mathrm{BB} 1$ (31 July 2006) and for BB2 (12 June 2007) with time domain reflectometry, and was about $0.18-0.2$ and $0.45-0.55$, respectively. The 14 days antecedent precipitation sum before application was $60.6,89.0$ and $175.2 \mathrm{~mm}$ for BB1, BB2 and $\mathrm{BB} 3$, respectively. The plots $\mathrm{BB} 1$ and $\mathrm{BB} 3$ received additional precipitation during the day before excavation (BB1: $21.0 \mathrm{~mm}$, BB3: $2.8 \mathrm{~mm}$ ). Brilliant Blue was applied in quantities of 20,40 and 301 , with a concentration of $4 \mathrm{~g} \mathrm{l}^{-1}$ to the plots BB1 $\left(1 \mathrm{~m}^{2}\right), \mathrm{BB} 2\left(2 \mathrm{~m}^{2}\right)$ and BB3 $\left(1 \mathrm{~m}^{2}\right)$, respectively. Application of tracer solution and additional water complies with input rates of $150 \mathrm{~mm} \mathrm{~h}^{-1}$. Soil profiles were excavated in horizontal and vertical layers the following day and photographs of the dye patterns under a $10 \mathrm{~cm}$ grid scale were taken with a digital camera. The images were analysed after Zehe and Flühler (2001a) and Blume et al. (2008), in- 
cluding rectification of the image, adjusting the tone curves to increase the contrast between stained and non-stained areas and computing a binary representation of the picture that allows determination of percent dye coverage.

\subsection{Data manipulation and analysis}

\subsubsection{Estimation of tracer concentrations and treatment of time series}

The time series of tracer signals (both fluorimeter and conductivity meter) and discharges were smoothed using a moving median function and turned to regular series in one minute values by taking each minute's median (tracer data) or linear interpolation (discharge data), except for the first hillslope tracer experiment where the fluorimeter measurement intervals of 120 s were used as a time base for all series. Calibrations were conducted in situ for each fluorimeter before and after each experiment. The calibrations resulted in linear relationships of signal and tracer concentrations in the range of $0-1000 \mu \mathrm{g} \mathrm{l}^{-1}\left(r^{2}>0.99\right)$. Background signals were subtracted from fluorimeter readings before determining fluorescence tracer concentrations. To determine salt tracer concentrations from conductivity meter readings, we calibrated the increase in electrical conductivity against concentrations of the applied salt tracer. The background conductivity, which was determined under rainfall simulation conditions before salt tracer was introduced into the system, was subtracted from the measured conductivity readings. Calibrations resulted in linear relationships of electrical conductivity and salt concentration in the range of $0-4 \mathrm{gl}^{-1}\left(r^{2}>0.99\right)$.

\subsubsection{Transfer function approach}

For analysis of tracer breakthrough curves (BTCs), we adopted the transfer function approach, which is based on the probability density function (PDF) of the tracer travel times $t$ along the transport distances $l$ (see Jury and Roth, 1990). In the case of a nonreactive solute added as a narrow pulse to a system under steady-state water flow, the travel time PDF, $f^{f}(l, t)$, is equal to the normalised outflow flux concentration, $C^{f}(l, t)$, and is defined as

$$
f^{f}(l, t)=\frac{C^{f}(l, t)}{\int_{0}^{\infty} C^{f}(l, \tau) d \tau}
$$

To construct the travel time PDFs, mass fluxes $C^{f}(l, t)$ $\left[\mathrm{g} \mathrm{s}^{-1}\right]$ were determined by multiplying effluent tracer concentration $\left[\mathrm{g}^{-1}\right]$ and discharge $\left[1 \mathrm{~s}^{-1}\right]$ when discharge measurements were available. The time integral of mass fluxes equals the recovered tracer masses, and the ratio of mass flux to total tracer mass gives a PDF of tracer travel times along the transport distance. Mass fluxes were normalised using the total mass of tracer recovered during the measurement, such that the integral of the PDF is unity. The travel time PDF allows conclusion on the transport regime alonglthrough its moments, e.g. mean travel time and travel time variance, cf. Eqs. (3) and (4). Trapezoidal rule integration was used for moment estimation as suggested by Haas (1996). To allow for a consistent determination of moments and comparability between experiments, the travel time PDF was constructed from tracer BTCs truncated to $0.1 \%$ of maximum concentration in the tailing.

Specific process representations of the travel time PDF can be derived for respective boundary and initial conditions (Jury and Roth, 1990). The most commonly used process model for solute movement in porous media is the convection-dispersion equation (CDE). A compilation of transfer function representations for the $\mathrm{CDE}$ is given by van Genuchten and Alves (1982). The CDE describes solute transport in the well-mixed case such that each solute molecule experiences the complete range of transport velocities during the transport process. Linear adsorption is the simplest model of an adsorbing tracer, assuming instantaneous equilibrium between solute concentrations in the adsorbed and liquid phase. Transport of a sorbing solute is then retarded, compared to a non-sorbing solute, by a constant retardation factor $R$. The corresponding transfer function representation of the one-dimensional CDE with linear adsorption for a Dirac delta upper boundary condition corresponding to the narrow input pulse is

$$
f^{f}(l, t)=\frac{l \sqrt{R}}{2 \sqrt{\pi D t^{3}}} \exp \left(-\frac{(R l-V t)^{2}}{4 D R t}\right)
$$

where $V$ is the pore water velocity $\left[\mathrm{m} \mathrm{s}^{-1}\right], D$ is the dispersion coefficient $\left[\mathrm{m}^{2} \mathrm{~s}^{-1}\right]$ and $R$ is the retardation coefficient.

The parameters of the CDE are related to the mean travel time $E_{l}(t)$ and travel time variance $\operatorname{Var}_{l}(t)$ of the travel time PDF (Das et al., 2005) such that

$$
\begin{aligned}
& E_{l}(t)=\int_{0}^{\infty} t f^{f}(l, t) d t=\frac{l R}{V} \\
& \operatorname{Var}_{l}(t)=\int_{0}^{\infty}\left(t-E_{l}(t)\right)^{2} f^{f}(l, t) d t=\frac{2 D l R^{2}}{V^{3}}
\end{aligned}
$$

The parameters of the CDE can thus be derived directly from the travel time PDF using Eqs. (3) and (4) when either $V$ or $R$ can be assumed known. Alternatively, the parameters can be estimated by fitting an analytical solution, e.g. Eq. (2), to the travel time PDF constructed from the measured BTC. For this approach we made use of the computer code CXTFIT (Toride et al., 1999). The parameters $V, D$ and $R$ are highly correlated, and one parameter has to be kept fixed for a successful fitting procedure. Constraints on parameter ranges were used in CXTFIT to limit $V$ to a range of values corresponding to the Darcy velocity, estimated from flow measurements, and assuming mobile water contents of 0.1 and 0.6 , respectively. 
Table 3. Soil block experiment and second hillslope experiment: velocities corresponding to time of first breakthrough, peak of tracers and mean travel time (first moment of travel time PDF), travel time variance (second central moment) and tracer recovery (\% mass applied).

\begin{tabular}{lrrrrrr}
\hline & $\begin{array}{r}\text { Distance } \\
{[\mathrm{m}]}\end{array}$ & $\begin{array}{r}\text { Breakthrough } \\
\text { velocity } \\
{\left[\mathrm{m} \mathrm{s}^{-1}\right]}\end{array}$ & $\begin{array}{r}\text { Peak } \\
\text { velocity } \\
{\left[\mathrm{m} \mathrm{s}^{-1}\right]}\end{array}$ & $\begin{array}{r}\text { Mean travel } \\
\text { velocity } \\
{\left[\mathrm{m} \mathrm{s}^{-1}\right]}\end{array}$ & $\begin{array}{r}\text { Travel time } \\
\text { variance } \\
{\left[\mathrm{s}^{2}\right]}\end{array}$ & $\begin{array}{r}\text { Recovery } \\
\text { (corrected BTC) } \\
{[\%]}\end{array}$ \\
\hline Soil block & & & & & & \\
Uranine 1 & 0.35 & $1.17 \times 10^{-3}$ & $1.72 \times 10^{-4}$ & $9.68 \times 10^{-6}$ & $2.77 \times 10^{9}$ & 22.02 \\
Uranine 2 & 0.35 & $2.33 \times 10^{-3}$ & $4.32 \times 10^{-4}$ & $8.49 \times 10^{-5}$ & $1.11 \times 10^{7}$ & $5.18(6.07)$ \\
Salt 1: $\mathrm{NaCl}$ & 0.35 & $5.83 \times 10^{-3}$ & $1.46 \times 10^{-3}$ & $2.07 \times 10^{-4}$ & $6.81 \times 10^{6}$ & 89.23 \\
Salt 2: $\mathrm{NaCl}$ & 0.35 & $2.92 \times 10^{-3}$ & $1.17 \times 10^{-3}$ & $7.22 \times 10^{-4}$ & $6.48 \times 10^{4}$ & 81.50 \\
Hillslope scale: Cut-bank & & & & & \\
Uranine 1 & 28.7 & $1.04 \times 10^{-2}$ & $3.95 \times 10^{-3}$ & $9.65 \times 10^{-4}$ & $5.40 \times 10^{8}$ & $2.9(2.93)$ \\
Uranine 2 & 28.7 & $7.97 \times 10^{-3}$ & $3.80 \times 10^{-3}$ & $1.16 \times 10^{-3}$ & $2.37 \times 10^{8}$ & $7.87(14.18)$ \\
Salt 1: $\mathrm{NaCl}$ & 8.2 & $1.37 \times 10^{-2}$ & $2.63 \times 10^{-3}$ & $5.93 \times 10^{-4}$ & $2.20 \times 10^{8}$ & 94.18 \\
Salt 2: $\mathrm{NaCl}$ & 16.9 & $8.54 \times 10^{-3}$ & $1.18 \times 10^{-3}$ & $7.51 \times 10^{-4}$ & $1.37 \times 10^{8}$ & 32.1 \\
Hillslope scale: Spring & & & & & & \\
Uranine 1 & 44.2 & $2.73 \times 10^{-2}$ & $1.62 \times 10^{-3}$ & $1.15 \times 10^{-3}$ & $6.75 \times 10^{8}$ & 0.45 \\
Uranine 2 & 44.2 & $3.78 \times 10^{-3}$ & $3.42 \times 10^{-4}$ & $1.32 \times 10^{-3}$ & $2.10 \times 10^{8}$ & 0.86 \\
Salt 1: $\mathrm{NaCl}$ & 23.7 & $4.49 \times 10^{-3}$ & $2.18 \times 10^{-3}$ & $5.18 \times 10^{-4}$ & $9.66 \times 10^{8}$ & 7.45 \\
Salt 2: $\mathrm{NaCl}$ & 32.4 & $2.07 \times 10^{-3}$ & $8.71 \times 10^{-4}$ & $6.48 \times 10^{-4}$ & $4.47 \times 10^{8}$ & 3.46 \\
\hline
\end{tabular}

Once the mean travel velocity and the dispersion coefficients are derived, the transport regime can be characterised by means of the Péclet number, which is defined as $P e=V l D^{-1}$ and gives the relative importance of advective to dispersive transport processes.

\section{Results}

\subsection{Soil block laboratory experiments}

The excavated soil block was subjected to unit gradient conditions with steady flow rates of $3.75 \mathrm{ml} \mathrm{s}^{-1}$ before and during the first uranine experiment and $6.0 \mathrm{ml} \mathrm{s}^{-1}$ during the other tracer experiments. These flow rates correspond to hydraulic conductivities of $2.4 \times 10^{-5}$ to $1.2 \times 10^{-4} \mathrm{~m} \mathrm{~s}^{-1}$, which is in good accordance with field-saturated hydraulic conductivities determined in situ (Sect. 2.1). The $\mathrm{pH}$ of the outflow ranged between 7.6-7.8.

The four tracer experiments resulted in single peaked BTCs (Fig. 2), although loss of data due to technical problems led to a gap in the BTC of the second uranine experiment. High breakthrough and peak velocities were observed for both uranine and sodium chloride (Table 3). Peak velocities were slower for the first uranine experiment, which can be attributed to lower flow rates. Transport velocities were slightly higher for salt tracers and their maximum recovery was $89.2 \%$, while only $22 \%$ of the uranine was recovered at most (Table 3). A decrease in flow rate caused an increase in uranine concentrations. However, a flow interrup-
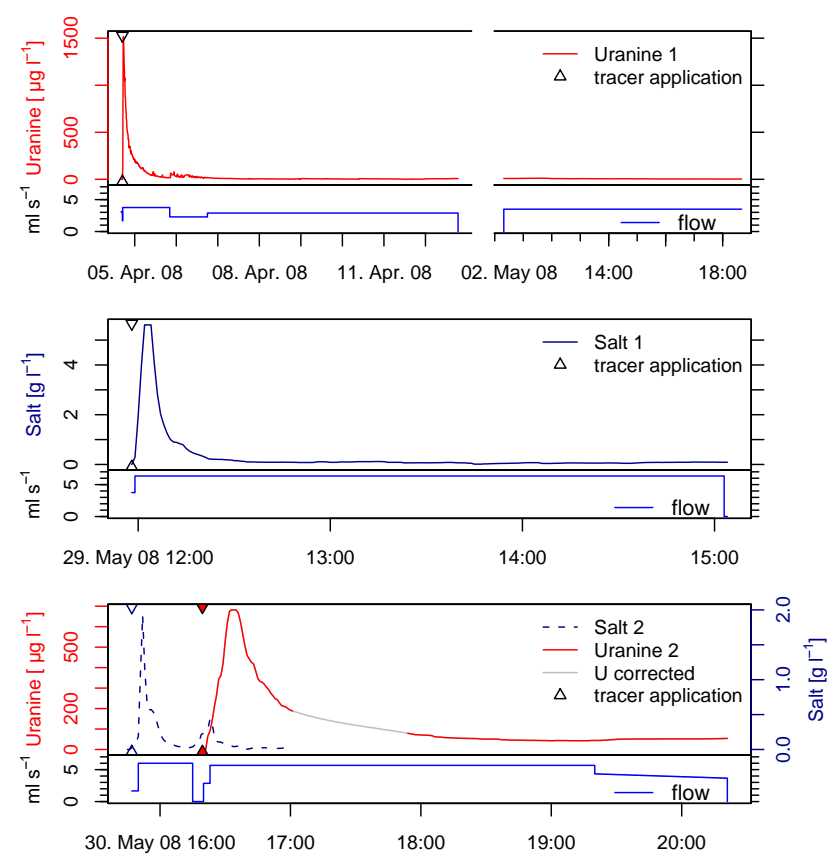

Fig. 2. Soil block experiments: tracer breakthrough curves (uranine and $\mathrm{NaCl}$ ) and water flows of three subsequent runs (times are Central European Time). The soilblock was flushed with tracer free water before each run, and inflow was interrupted for 19 days during the first run. A gap in the second uranine BTC (lower panel) was corrected using spline interpolation for a second estimate of tracer recovery (Table 3 ). 
Table 4. Results from fitting of CDE parameters for soil block experiment and second hillslope experiment: $R, V$ and $D$ (fixed values are printed italic), $r^{2}$, coefficient of determination of regression of observed against predicted data, and corresponding Peclét numbers $P e$.

\begin{tabular}{lrrrrrr}
\hline & $\begin{array}{r}\text { Distance } \\
{[\mathrm{m}]}\end{array}$ & $\begin{array}{r}R \\
{[-]}\end{array}$ & $\begin{array}{r}V \\
{\left[\mathrm{~m} \mathrm{~s}^{-1}\right]}\end{array}$ & $\begin{array}{r}D \\
{\left[\mathrm{~m}^{2} \mathrm{~s}^{-1}\right]}\end{array}$ & $\begin{array}{r}r^{2} \\
{[-]}\end{array}$ & $\begin{array}{r}P e \\
{[-]}\end{array}$ \\
\hline Soil block & & & & & & \\
Salt 1: $\mathrm{NaCl}$ & 0.35 & 1 & $5.34 \times 10^{-4}$ & $7.21 \times 10^{-5}$ & 0.91 & 2.59 \\
Salt 2: $\mathrm{NaCl}$ & 0.35 & 1 & $6.84 \times 10^{-4}$ & $4.05 \times 10^{-5}$ & 0.76 & 5.92 \\
Uranine 2 & 0.35 & 28.5 & $6.84 \times 10^{-4}$ & $7.75 \times 10^{-4}$ & 0.94 & 0.31 \\
Uranine 1 & 0.35 & 28.5 & $1.24 \times 10^{-4}$ & $2.36 \times 10^{-4}$ & 0.97 & 0.18 \\
Hillslope scale: & Cut-bank & & & & & \\
Uranine 1 & 28.7 & 1 & $8.70 \times 10^{-4}$ & $1.57 \times 10^{-2}$ & 0.92 & 1.59 \\
& & 28.5 & $2.48 \times 10^{-2}$ & $4.47 \times 10^{-1}$ & 0.92 & 1.59 \\
& & 0.63 & $5.55 \times 10^{-4}$ & $9.92 \times 10^{-3}$ & 0.92 & 1.60 \\
Uranine 2 & 28.7 & 1 & $9.82 \times 10^{-4}$ & $1.22 \times 10^{-2}$ & 0.85 & 2.31 \\
& & 28.5 & $2.80 \times 10^{-2}$ & $3.47 \times 10^{-1}$ & 0.85 & 2.31 \\
Salt 1: $\mathrm{NaCl}$ & 8.2 & 1 & $5.55 \times 10^{-4}$ & $4.13 \times 10^{-3}$ & 0.95 & 1.10 \\
Salt 2: $\mathrm{NaCl}$ & 16.9 & 1 & $5.91 \times 10^{-4}$ & $2.96 \times 10^{-3}$ & 0.80 & 3.38 \\
Hillslope scale: Spring & & & & & & \\
Uranine 1 & 44.2 & 1 & $1.28 \times 10^{-3}$ & $9.71 \times 10^{-3}$ & 0.49 & 5.83 \\
Uranine 2 & & 28.5 & $3.65 \times 10^{-2}$ & $2.77 \times 10^{-1}$ & 0.49 & 5.83 \\
Salt 1: $\mathrm{NaCl}$ & 24.2 & 1 & $1.18 \times 10^{-3}$ & $8.41 \times 10^{-3}$ & 0.86 & 6.22 \\
Salt 2: $\mathrm{NaCl}$ & 32.4 & 1 & $6.15 \times 10^{-4}$ & $2.69 \times 10^{-3}$ & 0.85 & 7.41 \\
\hline
\end{tabular}

tion during experiment Uranine 1 did not significantly affect uranine concentrations in the outflow; median concentrations one hour before and after an interruption of $19 \mathrm{~d}$ were 8.4 and $8.7 \mu \mathrm{gl}^{-1}$, respectively (Fig. 2).

The PDFs resulting from the tracer BTCs are shown in Fig. 5 together with the corresponding solutions of the onedimensional CDE with parameters estimated from the moments of the PDFs (Table 3), and parameters from fitting of Eq. (2), respectively (Table 4). Slower velocities of uranine indicate a possible retardation of the fluorescence tracer. Thus, first the parameters $V$ and $D$ were fitted for the salt tracers assuming conservative behaviour of chloride $(R=1)$. Then, the pore water velocity obtained from the fit for experiment Salt 2 were used for fitting $R$ and $D$ for experiment Uranine 2, and finally, the $R$ obtained was used for fitting $V$ and $D$ for experiment Uranine 1. A retardation factor $R=28.5$ was found for Uranine 2, which also gave a reasonable parameter set for experiment Uranine 1 (Table 4), although the fitted $V$ was at the lower limit of the parameter constraints.

\subsection{First hillslope tracer experiment under natural rainfall conditions}

The hillslope tracer experiment in 2006 was originally designed as a preliminary study to test hydraulic connections between the hillslope surface and the spring. Rainfall simulation was run successfully at four plots on the hillslope (Fig. 1), but natural rainfall increasingly superimposed the applied rates during the course of the experiment. The effect of the applied rainfall on spring discharge was clearly minor compared to natural rainfall. In contrast, both rainfall simulation and natural rainfalls with similar intensities $\left(12 \mathrm{~mm} \mathrm{~h}^{-1}\right)$ generated complete saturation of the top $0.5 \mathrm{~m}$ at plot II within $1 \mathrm{~h}$. Fast seepage flow was observed after intensification of rainfall from soil pipe outlets at a cut-bank (approximately $1.50 \mathrm{~m}$ height, $1.20 \mathrm{~m}$ width) where a hiking trail cuts the hillslope $11 \mathrm{~m}$ upslope of the spring. Exfiltration and surface runoff concentration have also been observed at a few other locations along the trail, but less pronounced and in comparably minor amounts. Therefore, the fluorimeters for sulforhodamine $\mathrm{G}$ was moved to the cut-bank to collect tracer data from these flow compartments, although no discharge measurements were available at this location. 
In this first experiment salt tracers were applied at plots II and III, and the input of fluorescent tracers was split between plots IV and I with a lag of $30 \mathrm{~min}$ (Table 1). Uranine was observed in spring discharge only $7 \mathrm{~min}$ after the first application and reached its first peak after $351 \mathrm{~min}$. Sulforhodamine $\mathrm{G}$ at the cut-bank was observed $87 \mathrm{~min}$ after the first application, and the first peak was recorded after $107 \mathrm{~min}$. Both fluorescent dyes showed BTCs with multiple peaks of comparable maximum concentrations (Fig. 3). Neither chloride nor bromide could be detected with ion exchange chromatography on spring water samples. Electrical conductivities dropped below background due to strong dilution by natural rain water and impeded salt concentration estimations from electrical conductivity readings. Recovery for uranine at the spring was only $1.37 \%$ of applied mass. As no data on discharge at the cut-bank are available, no recovery could be estimated for sulforhodamine G. Nevertheless, the qualitative dynamics of tracer transport were captured by both BTCs. Correlation analysis revealed an overall positive correlation of tracer breakthrough to rainfall and spring discharge (Table 2). Spring discharge, uranine and sulforhodamine $\mathrm{G}$ were correlated to rainfall with time lags of 2520, 2400 and $240 \mathrm{~s}$, respectively. Likewise, both tracer BTCs were correlated to spring discharge (uranine: zero time lag; sulforhodamine $\mathrm{G}$ at the cut-bank: $-2400 \mathrm{~s}$ time lag), which indicates that the same flow field is observed at the two locations, but at different distances. Interestingly, the corresponding correlation coefficients were even higher for the period after the rainfall simulations, while the same variables were negatively or at least less correlated during rainfall simulation. Uranine concentration was inversely proportional to spring discharge during the simulation $(r=-0.62)$ and positively correlated afterwards $(r=0.64)$. Sulforhodamine $\mathrm{G}$ was more strongly correlated to (effective) rainfall and to spring discharge after the simulations were stopped (Table 2). Spring discharge was correlated to natural rainfall $(r=0.55)$ and uncorrelated to effective rainfall during the simulations with a time lag of $2520 \mathrm{~s}$; instead, the correlation with natural rainfall was stronger during the simulations $(r=0.70)$ with a longer time $\operatorname{lag}(5400 \mathrm{~s})$.

\subsection{Second hillslope tracer experiment under steady-state flow conditions}

The second hillslope tracer experiment at the study site was conducted one year after the first experiment with largely the same setup (Fig. 1), only plot IIIa was moved $10 \mathrm{~m}$ to plot IIIb to be situated in line with the other plots. Additionally, discharge gauging of seepage flow at the cut-bank was installed. The rainfall simulation on the four plots (without natural rainfall input) were sufficient to produce seepage flow at the cut-bank, which began 22 min after starting the sprinklers and reached an approximate steady-state of $0.08-0.101 \mathrm{~s}^{-1}$ after $142 \mathrm{~min}$. Seepage flow stopped completely $120 \mathrm{~min}$ after stopping the sprinklers. Spring dis-
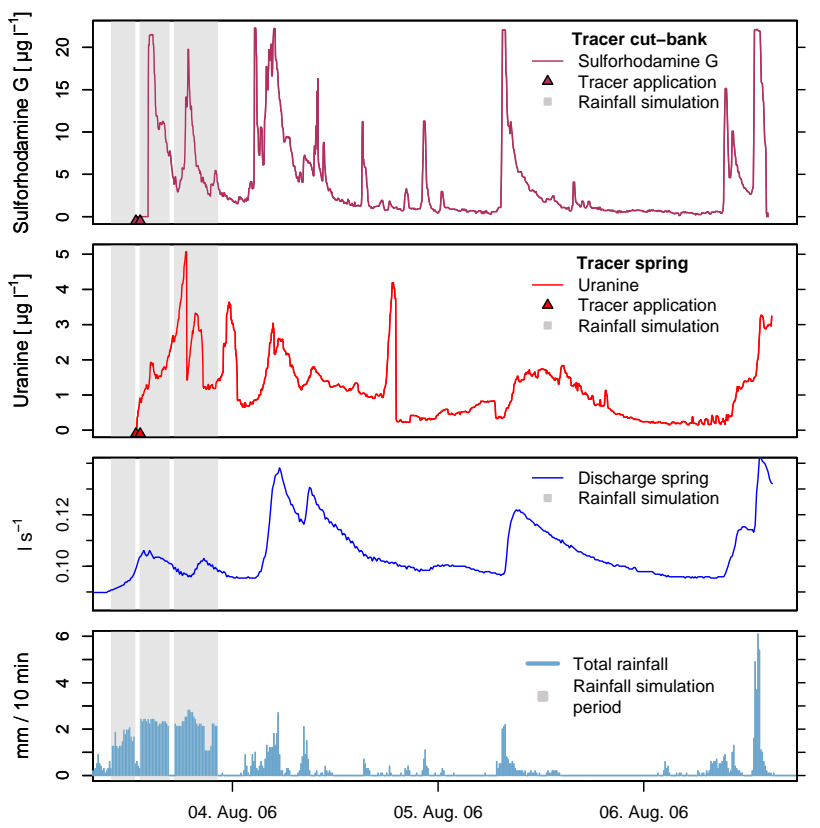

Fig. 3. First hillslope experiment under natural rainfall conditions: Tracer breakthrough curves (sulforhodamine $\mathrm{G}$ in outflow at cutbank, uranine in spring discharge), spring discharge and total rainfall (from top to bottom). Grey shading marks the rainfall simulation period.

charge, which had been receding, levelled off at a steadystate of $0.081 \mathrm{~s}^{-1}$ during the rainfall application and continued in recession afterwards. At both locations, natural rainfalls occurred after the rainfall simulations and produced much higher discharges (Fig. 4).

Uranine and sodium chloride were used as tracers in this second experiment. They were added by night at plots IIIb and I, respectively, and the applications were repeated after $45 \mathrm{~h}$ at plots IIIb and II (Table 1). The resulting tracer BTCs are shown in Fig. 4. Uranine concentrations at the cut bank showed sudden jumps during the transition phase of seepage flows between the two experimental parts, which exemplifies the inverse relation of flow and tracer concentrations. A sudden shift in uranine concentrations occurred during the second stage of the experiment, presumably due to technical problems with the inflow to the fluorimeter. The data from this period were omitted from further analysis. A manually corrected complete series was used for a second assessment of tracer recovery (Table 3 ) and for illustration purposes (Fig. 4).

Breakthrough was generally fast and resulted in smooth BTCs. Astonishingly, the fastest breakthrough occurred along the longest travel distance, i.e. uranine in the spring, which was even faster than the salt tracers with shorter travel distances. Velocities of the latter were in the same order of magnitude as the breakthrough velocities of the tracers at the cut-bank (Table 3). These results indicate that the 

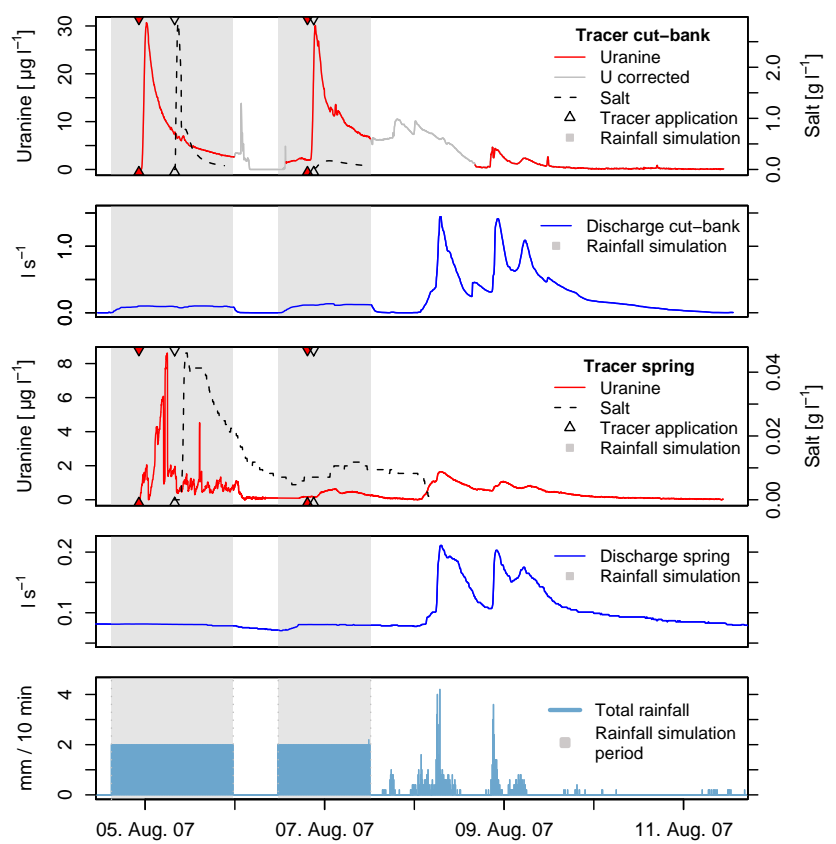

Fig. 4. Second hillslope experiment under steady flow conditions: tracer breakthrough curves for uranine and $\mathrm{NaCl}$ at the cut-bank, discharge at the cut-bank, tracer BTCs of uranine and $\mathrm{NaCl}$ in spring discharge, discharge at spring, and total rainfall (from top to bottom). Grey shading marks the rainfall simulation period. Parts of the uranine BTC at the cut-bank were distorted due to insufficient inflow to the fluorimeters and were excluded from further analyses; the manually corrected data were used for a second estimate of recovery (Table 3 ).

experiments under steady-state conditions essentially sampled the same flow field, except for uranine in the spring which appears to have followed a special short-circuit. We can roughly estimate a bulk saturated hydraulic conductivity of the entire transport domain from the tracer BTC by assuming water flow is parallel to the ground surface. Average tracer velocity is equal to the Darcy velocity divided by porosity, while Darcy velocity is hydraulic conductivity multiplied with hydraulic gradient. We can approximate the hydraulic gradient in steady-state conditions by the topographic gradient, which here is about $0.5(30 \mathrm{~m} / 60 \mathrm{~m}$; Fig. 1b). Considering bulk porosity as 0.5 , we obtain that bulk hydraulic conductivities are identical to the observed mean tracer velocities (Table 3).

Tracer recoveries were $3.4 \%$ for uranine and $101.6 \%$ for salt after the first part of the experiment (Table 3). For the second part, recovery of salt tracer estimated from conductivity measurements was considerably lower, which can only partly be explained by dilution with natural rain after the rainfall simulation. Uranine recovery was higher for the second part $(8.7 \%)$.
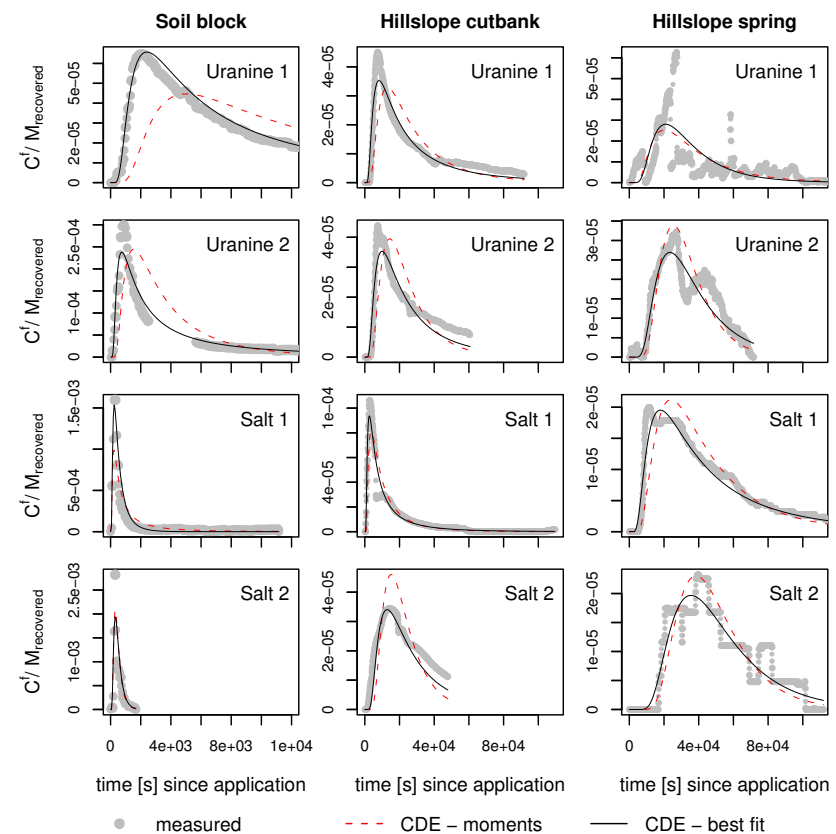

Fig. 5. Travel time probability functions of soil block experiments and second hillslope tracer experiments with uranine and $\mathrm{NaCl}$. The PDFs were derived from the measured breakthrough curves and modelled with the convection-dispersion equation, parameterised either with the moments of the measured BTC or fitted parameters.

The PDFs obtained from the BTCs were analysed by determination of moments and fitting to the one-dimensional CDE (Fig. 5). Fitting the uranine BTC with the retardation factor $R=28.5$ found for uranine in the soil block experiments yielded implausible high values of $V$ and $D$. Likewise, fitting the uranine BTC with values for $V$ obtained from salt BTC yielded values of $R<1$ (Table 4). These results imply that at the hillslope scale the mobile fraction of uranine was not retarded compared to salt tracers.

\subsection{Dye staining experiments}

Three staining dye tracer experiments were conducted in situ to visualise infiltration and flow patterns. The excavated soil profiles revealed significantly different flow patterns in the top $10 \mathrm{~cm}$ and the underlying layer(s).

Experiment BB1 (Fig. 6a) showed a quite uniform infiltration pattern into the top soil layer to a depth of $2 \mathrm{~cm}$. Dye coverage was $36 \%$ of horizontal area, mainly at the centre of the plot. At depths of 5 to $10 \mathrm{~cm}$, flow patterns concentrated to $18 \%$ of the cross section (Fig. 6c). Below $10 \mathrm{~cm}$ depth, desiccation cracks with apertures up to $1.5 \mathrm{~cm}$ were found to dominate percolation patterns. The stained cross sections were $20 \%$ (10 cm depth), 16\% (15 cm depth) and $21 \%$ (25 cm depth), respectively. The cracks formed polyhedrons $10-20 \mathrm{~cm}$ in diameter and extended down to bedrock at 30$50 \mathrm{~cm}$ depth, where the dye solution followed the irregular 
bedrock surface (Fig. 6d). The walls of the cracks were not only stained by the dye, but also dark coatings due to illuvation of clay and organic matter were found, which indicate the persistence of these structures.

Experiment BB2 showed comparable flow patterns. Horizontal cross sections exhibit very similar percentages of dye coverage at different depths (51\% in $3 \mathrm{~cm}$ and $49 \%$ in $10 \mathrm{~cm}$ and $20 \mathrm{~cm}$, respectively). Similar to BB1, an increasing concentration in the flow patterns with depth was found. Additionally, pipes with diameters of $0.8-4.8 \mathrm{~cm}$ were stained by the infiltrated dye solution (Fig. 6b). In vertical cross sections the largest pipe $(2.6 \times 3.2 \mathrm{~cm}$ at $10 \mathrm{~cm}$ depth; $3.8 \mathrm{~cm}$ in diameter at $25 \mathrm{~cm}$ depth) was found to extend from the soil surface to $5 \mathrm{~cm}$ above bedrock at $50 \mathrm{~cm}$ depth $(3.9 \times 4.8 \mathrm{~cm})$, where it changed its orientation from vertical to horizontal. Another stained root pipe above the bedrock surface was $4.2 \mathrm{~cm}$ in diameter. Smaller root pipes $(0.8-1.2 \mathrm{~cm}$ wide) were found in 25 and $35 \mathrm{~cm}$ depth. Stained desiccation cracks were found in the vertical cross sections below the humus rich horizon in the top $15 \mathrm{~cm}$; even though these were less prominent than in BB1 and crack apertures were below $0.5 \mathrm{~cm}$.

A similar pattern for the top $15 \mathrm{~cm}$ of the soil was found in experiment BB3. However, a large living tree root at $15 \mathrm{~cm}$ depth hampered excavation below that depth. Lateral flow along the root as well as ponding and lateral flow at the transition of soil layers at $10-15 \mathrm{~cm}$ depth were found to dominate the flow pattern at this plot.

\section{Discussion}

Salt and dye tracers have been applied in this study to investigate the complex hydrological processes in the vadose and saturated zone under heavy rainfall at the hillslope scale. In the following sections, inferences on the hydrological functioning of the studied hillslope are drawn from the experimental results, and the methodological approach is discussed.

\subsection{Hillslope characteristics}

Together with findings from dye staining at selected locations on the hillslope, the fast breakthrough of tracers at the hillslope scale can readily be attributed to subsurface stormflow via a network of preferential flow paths. Dye staining showed that infiltration is high and spatially uniform in the upper $(0-15 \mathrm{~cm})$ organic-rich soil layer, and flow converges into preferential flow paths such as root pipes and desiccation cracks in lower horizons. The observations further indicate that these features persist on larger timescales, which suggests that frequent flow aids in sustaining the structures of these features. In connection with percolation through these discrete structures, lateral preferential flow also occurs along the bedrock surface (Fig. 6a, d). This general conceptual model that emerges from the results of the dye staining
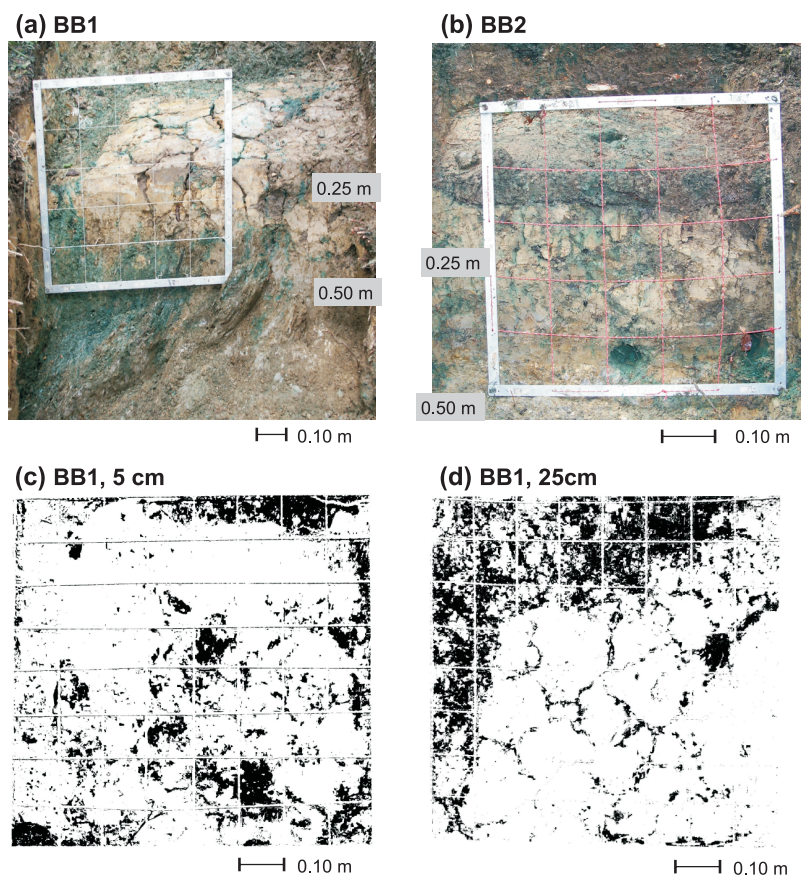

Fig. 6. Dye staining experiments (for location cf. Fig. 1): (a) photograph of soil profile BB1 showing cracks and dye-stained bedrock (horizontal section in $0.25 \mathrm{~m}$ depth and vertical section from $0.25-$ $0.50 \mathrm{~m}$ ). (b) Photograph of soil profile BB2 showing pipes of several $\mathrm{cm}$ in the topsoil and above bedrock (horizontal section in $0.10 \mathrm{~m}$ depth and vertical section from $0.10-0.50 \mathrm{~m})$. (c), (d): binarized horizontal cross-sections ( 0.05 and $0.25 \mathrm{~cm}$ below surface) of soil profile BB1 showing stained areas in dark.

experiments is consistent with findings from other hillslopes which highlight the importance of preferential flow in macropores (Mosley, 1979; Sidle et al., 2001; Tsuboyama et al., 1994) and bedrock characteristics (Freer et al., 2002; Trompvan Meerveld et al., 2007; Uchida et al., 2002) for SSF formation. Although dye staining can also provide valuable insights about the types of preferential flow paths at the scale of an entire hillslope (Anderson et al., 2009; Noguchi et al., 1999), the method is highly invasive and therefore limited in its applicability. The experiments cannot be reproduced for the same location, and it does not provide information on the temporal dynamics of flow processes.

The transport experiments with applied tracers provide a complementary means to investigate the effective functioning of preferential pathways under SSF conditions at the hillslope scale and hence to refine the conceptual model (Joerin et al., 2005; Kienzler and Naef, 2008a; Stamm et al., 2002). The spatial arrangement and internal connectivity of the preferential network constitute first-order controls on the hydrological response of the hillslope which are not apparent from plot scale experiments. This is exemplified by fast tracer breakthrough in all of our hillslope experiments, which shows that all four randomly selected application plots 
are connected to both of the two measurement locations via a network of preferential flow paths, while the quantity of tracer actually entering these paths varied considerably between different application plots. Breakthrough of tracers into the perennial spring shows that the bedrock aquifer is connected to preferential flow paths in the soil layers. Furthermore, transport of uranine to the spring was the fastest of all observations, despite the longest flow distance, which indicates the existence of zones of high vertical permeability in the bedrock layer. The differences in transport characteristics, e.g. the variability of flow velocities about one order of magnitude (Table 3), emphasise the specificity of flow paths connecting different locations along the hillslope. Mean tracer velocities were in this case found to directly give an estimate of the bulk hydraulic conductivities (Sect. 3.3). These are at least as high as the conductivities measured in situ for the top soil (Sect. 2.1), although they are integrating over a considerably larger domain. The preferential flow paths thus appear to be connected across the entire hillslope.

The importance of the connectivity of the preferential flow network is again highlighted by the first hillslope experiment under natural rainfall conditions, where tracer breakthrough occurred in the form of multiple peaks of comparable concentrations. Mass recovery for uranine was very low, even when normalised to maximum recovery rate of the soil experiment, most likely due to incomplete sampling of the entire set of possible flow paths due to the superimposed natural rainfall (Sect. 4.2). However, for the BTC of the observed subset of tracer, a clearly positive correlation of tracer concentration to rainfall and spring discharge was found instead of dilution effects (Table 2). This counterintuitive finding is not evident from the steady-state experiments with rainfall simulations at selected plots, and thus can be attributed to differences in total amount and spatial and temporal distribution of inputs. Natural rainfall over a wider area leads to activation of additional flow paths and the extension of the converging preferential flow network. Hence, the horizontal connectivity of the network is determined by the spatial arrangement of singular structures and the spatial distribution of rainfall.

This corroborates findings of other authors who report direct response of tracer transport to rainfall inputs and correlation of concentrations with peak discharges. For example, pesticide transport at the sub-watershed scale showing similar characteristics was related to surface and subsurface flow processes which were controlled by rainfall intensity (Leu et al., 2005, 2004). Luxmoore et al. (1990) and Wilson et al. (1991) observed similar transport behaviour at forested hillslopes and attributed that to the development of perched water tables and changing lengths of the subsurface flow paths. The occurrence of multiple peaks indicates that tracers were delivered continuously out of some sort of reservoir, as e.g. the soil matrix (McDonnell, 1990), a topsoil reservoir (McGrath et al., 2008) or a temporarily stagnant perched water table, e.g. in depressions in bedrock (Tromp- van Meerveld and McDonnell, 2006). As no evidence for temporary storage in the soil was found in the laboratory experiments, the latter mechanism is the most likely: intermittent tracer breakthrough results directly from alternate transport and storage of tracers in discrete structures of the preferential flow network.

\subsection{Tracer method and mass recovery}

Fluorescent dye tracers were chosen for this study because their specific properties allowed tracer concentrations to be determined with high temporal resolution and independently of each other in the same solution. In contrast, determination of salt tracers required either laboratory analysis of field samples with poor temporal resolution, or electrical conductivity measurements as an indirect estimation method, which does not allow independent determination of different species. Moreover, the latter method failed when background conductivities were strongly variable. Nevertheless, numerous studies have successfully applied salt tracers (e.g. Lange et al., 1996; Tsuboyama et al., 1994; Zehe and Flühler, 2001b), also based on other methods of measurement (e.g. Binley et al., 1996; McIntosh et al., 1999; Vanderborght et al., 2000), due to the fact that salt transport can be considered conservative.

The fluorescent dyes uranine and sulforhodamine $G$ are well known from previous hydrological studies (Käss, 1998; Stamm et al., 2002; Kienzler and Naef, 2008a). However, their use as tracers in the unsaturated zone is complicated by a variety of possible interactions with the soil to which they are applied. This includes adsorption, which can cause a partial loss and retardation of the tracers. Uranine is generally considered to be one of the least absorbing tracers for groundwater studies (Käss, 1998; Ptak and Schmid, 1996; Chua et al., 2007), while the degree of sorption depends on the characteristics of the solid phase. Uranine has negatively charged functional groups at neutral $\mathrm{pH}$ and thus easily sorbs onto positively charged surfaces, and hardly at all on anionic surfaces (Kasnavia et al., 1999). Furthermore, pH and soil chemistry can affect the fluorescence of the dyes, which may lead to underestimation of tracer concentrations at $\mathrm{pH}$ below 6.5 and chloride concentrations above $0.5 \mathrm{M}$ or electrical conductivity above $44.0 \mathrm{mS} \mathrm{cm}^{-1}$, respectively (Smart and Laidlaw, 1977; Chua et al., 2007). Consistently, different studies in the vadose zone have found considerable (Omoti and Wild, 1979a,b; Mikovari et al., 1995) or negligible (Chua et al., 2007; Kienzler and Naef, 2008a) sorption of uranine in the soils that were investigated.

In our experiments uranine transport was characterised by low recovery rates (Table 3 ), despite the relatively high input concentrations and high flow rates. Recovery was low in the soil block laboratory experiment (Uranine 1: 22\%) even after leaching with over 200 pore volumes. In contrast, the mass balances of the $\mathrm{NaCl}$ tracer were almost closed with $89.2 \%$ maximum recovery (considering the uncertainty related to concentration estimations from electrical conductivity data) 
after approximately 10 pore volumes. The low recovery of the uranine is thus neither due to early termination of the experiment and missing slow flow components nor to incomplete capture of outflow, given that both tracers followed the same population of flow paths. A flow interruption during the soil block laboratory experiment did not show an effect on uranine concentrations, which is a first indication the major influence of non-equilibrium transport processes, e.g. ratelimited sorption and desorption processes. Definite assessment of possible non-equilibrium transport of uranine in the soil block scale would require a set of further experiments, e.g. with controlled flow interruptions of different durations (Brusseau et al., 1997), which is beyond the scope of the present paper. Degradation of uranine is primarily by sunlight and secondarily by microbial decay (Käss, 1998), and can be precluded as alternative explanations as well, as the soil block experiment was not exposed to sunlight, and uranine had not been applied to the soil block before the first experiment, as is necessary for the development of a microbial community capable of degrading the dye. Likewise, a loss of fluorescence is not to be expected under the experimental conditions, where $\mathrm{pH}$ was neutral and electrical conductivities were below $12 \mathrm{mS} \mathrm{cm}^{-1}$. Thus, the physicochemical reasons for this apparent loss of a large fraction of the uranine remain unexplained. The most probable explanation is irreversible absorption by organic matter on and directly below the undisturbed soil surface (irreversible at least within the time scale of the experiments).

Fitting of soil block PDFs using flow rate constraints indicates that the mobile fraction of uranine might have additionally been retarded compared to chloride (Table 4). The BTCs and fits from the second hillslope experiment instead show that the mobile fraction of uranine has been transported with higher velocities than the salt tracers. Consequently, retardation due to reversible adsorption had not exerted a first-order control on the transport of the mobile fraction of uranine at the hillslope scale and we assume approximately conservative behaviour of the mobile fraction of the dye below the humus rich top soil layer.

The tracer BTCs are thus a reflection of the transport behaviour of the tracer fraction that was actually transported, not the tracer that was apparently stored in the soil by irreversible absorption. For further interpretation of the hillslope tracer experiments, maximum recovery should hence be expected to be $22 \%$ or less after percolation through the top soil layer $(0.35 \mathrm{~cm})$. This would imply recovery rates for the mobile uranine fraction of $6.22 \%$ for the first hillslope experiment, and $15.21 \%$ and $59.26 \%$ (91.96\% for corrected series, Fig. 4) for the second hillslope experiment, respectively. For the hillslope scale experiments, incomplete recovery can additionally result from incomplete capture of possible flow paths, and missing slow flow components due to the limited time of the measurements. These constrictions result from the limited controllability inherent to in situ-experiments at the hillslope scale, even when making unusual efforts to con- trol boundary conditions (e.g. Lange et al., 1996). Interestingly, under steady-state flow conditions the mass balance of $\mathrm{NaCl}$ applied nearest to the measurement locations (Fig. 1) was closed within the rainfall simulation period, while recovery was only $35.6 \%$ after a second application $8.2 \mathrm{~m}$ upslope (Table 3). Normalized recovery of uranine was lowest $(6.2 \%)$ under natural rainfall conditions in the first hillslope experiment, when the extent of the preferential flow network presumably was widest. Consequently, the BTCs and the resulting travel time PDFs are conditional on the distinct flow paths from the application plot to the measurement location and only resemble the mobile tracer fraction that was transported via the flow network under the given boundary conditions.

\subsection{Transfer function approach}

To analyse the tracer BTCs of the mobile tracers, we adopted a transfer function approach using the method of moments and a process model representation for the travel time PDFs. To allow for comparison between our experiments, we truncated the BTCs and normalised with recovered tracer masses to construct travel time PDFs with defined length and unit area.

The moments of a travel time PDF provide a measure for comparing different transport regimes without the need to make assumptions on the underlying physical processes. The estimation of moments, however, crucially depends on the regularity and completeness of the series used in the calculation. Complete mass recovery would ideally be required to estimate transport parameters reliably by the method of moments (Das et al., 2005), which is not the case for many tracer studies, including our experiments. The estimation of moments was additionally affected by non-regularities of the data, e.g. in the second soil block uranine experiment (Fig. 2). In comparison to a continuous series, simulated with spline interpolation, the incomplete PDFs yielded lower estimates of recovery and mean travel time (zeroth and first moment) and larger values of higher order moments.

Fitting a transfer function model to the travel time PDF is less sensitive to the regularity and truncation of the data. We investigated the one-dimensional equilibrium $\mathrm{CDE}$ as one illustrative example for an effective large-scale representation of micro-scale processes. This simple model describes wellmixed convective-dispersive solute transport under steadystate water flow in homogeneous soils in one spatial dimension. Another example of a simple process model representation would be the convective lognormal transfer function model for a stochastic-convective transport regime without mixing (Jury, 1982). The relationship of travel distances and moments of the PDFs can help to distinguish between both transport regimes. If tracer transport was in a convectivedispersive system with mixing lengths less than transport distances, travel time variance $\operatorname{Var}_{l}(t)$ would be increasing linearly with distance $l$, while $\operatorname{Var}_{l}(t)$ would increase propor- 

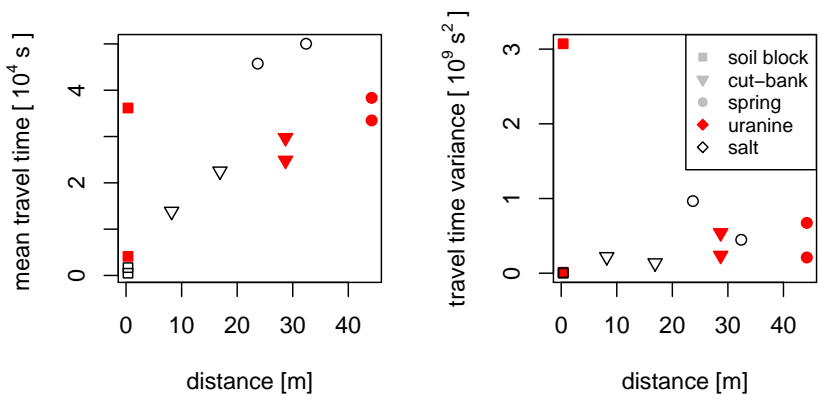

Fig. 7. Soil block and second hillslope tracer experiment: mean travel time (first moment; left) and travel time variance (second central moment; right) of travel time PDF vs. travel distance (individual experiments indicated by combination of symbol shape and filling).

tional to $l^{2}$ in the stochastic-convective case (Jury and Roth, 1990). The observations (Fig. 7) do not allow a clear distinction of the underlying relationship of travel time variance to distance, but simply assuming a linear trend would support the use of a CDE model in the first instance.

The differences between salt and uranine may be due to different transport behaviour of the tracers, or because different transport regimes are related to the differing flow paths in the hillslope experiment. As discussed above, retardation due to linear sorption cannot explain the differences in tracer behaviour. Other models of non-ideal transport that make use of non-linear process representations would provide different means to describe reactive solute transport.

Rate-limited sorption as an example for chemical nonequilibrium transport of reactive tracers was already discussed above. But for these approaches additional tracerspecific parameters would have to be determined. Moreover, both sorbing and nonsorbing solutes are also possibly affected by transport-related, i.e. physical non-equilibrium (Brusseau et al., 1997), e.g. solute exchange between mobile and immobile domains represented by preferential flow features and soil matrix. However, a one-dimensional mobileimmobile model did not provide more concordant fits to the BTCs of our experiments, but suggested the use of the equilibrium model instead. The fitted models for the soil block and in the second hillslope experiments, where water flows were settled to quasi-steady state, are mostly in good agreement with observed BTCs (75\% with $r^{2} \geq 0.85$ ). The optimised parameters are in comparable ranges within one group of tracers measured in different parts of one experiment, e.g. uranine tracers or salt tracers measured at the cut-bank and in the spring during the second hillslope tracer experiment (Table 4). The soil block experiments show that parameters additionally depend on flow rate. The comparability of results for different tracers is restricted by high correlation of parameters $V, D$ and $R$ in Eq. (2), which makes the numerical values of the parameters obtained by fitting highly dependent on the choice of fixed parameters. In con- trast, the Peclét number $P e$ is equal for different optimised parameter sets (Table 4) and thus is a robust measure for the transport regime. The $P e$ from the hillslope experiment are quite low (1.1-7.4), even after transport distances over $40 \mathrm{~m}$, which illustrates the highly dispersive nature of the transport medium. This range of $P e$ is consistent with results from plot scale experiments at a forested hillslope where $P e$ were in the range 0.8-3.3 (Tsuboyama et al., 1994). According to Germann (1991), much higher $\mathrm{Pe}$ ( $>72$ for a pulse tracer input) are required to justify the application of hydrodynamic dispersion as a model for the underlying microscale processes. The assumptions underlying the one-dimensional CDE are obviously strong simplifications, in particular for the hillslope scale. If it is employed as a functional description of solute transport notwithstanding, the resulting parameters do not necessarily have observable physical meaning (Jensen et al., 1996).

Advanced higher-dimensional and non-equilibrium models might provide a means to overcome these limitations, but also require much more information on tracer properties and soil characteristics. This also applies to the numerous numerical models, but these in turn offer the advantage of combining independent simulations of water flows and solute transport. Simulation studies hence would provide different means to understand how heterogeneities in rainfall and subsurface structures translate into BTCs of tracer experiments.

\section{Summary and conclusions}

Subsurface stormflow in response to heavy rainfall has been studied at a forested hillslope in the Austrian Alps using a combination of dye staining at the plot scale with rainfall simulations and tracer tests at the hillslope scale. Steep forested slopes constitute especially challenging environments for experimental work. For example, slope topography only allowed covering parts of the experimental area with rainfall simulations. Nevertheless, this setup was sufficient to produce subsurface flow within the hillslope and maintain quasi-steady state flow rates at a spring and a cut-bank downslope.

Salts $(\mathrm{NaCl}, \mathrm{NaBr})$ and fluorescent dyes (uranine, sulforhodamine $\mathrm{G}$ ) applied at the soil surface were suitable for tracing subsurface flow over distances of up to 32.4 and $44.2 \mathrm{~m}$, respectively. Despite the fine-textured soils, tracer breakthrough was fast in all experiments, with breakthrough velocities ranging from $1.0 \times 10^{-2}$ to $2.0 \times 10^{-3} \mathrm{~m} \mathrm{~s}^{-1}$. Breakthrough curves were measured in situ with high temporal resolution, which proved to be especially advantageous in the case of highly dynamic fluorescence tracers in transient flow conditions under natural rainfall. Under these circumstances salts were not appropriate as tracers, because estimations of concentrations via electrical conductivity and with ion chromatography were precluded due to strong dilution by rainwater. However, under 
simulated rainfall the breakthrough of salt tracers was captured well with electrical conductivity readings, and nearly complete recovery of tracer mass was achieved. In contrast, we found very low recovery rates of the fluorescent dyes during the hillslope experiments. Uranine tracer tests with an undisturbed soil block $(0.35 \mathrm{~m}$ depth) from the study area yielded similar low recovery rates. Although the reasons were not definitively clarified by our experiments, the apparent loss of tracer was evidently caused by interactions of dye and soil material in the top-most soil layers. This finding implies that tracers need to be selected carefully and checked for interactions with the specific soil material. From the soil block results we conclude that the hillslope scale BTC of the fluorescence tracers reflects the transport behaviour of the mobile tracer fraction only. Dye staining revealed that infiltration was quite uniform down to a depth of $0.15 \mathrm{~m}$, and that percolation below was dominated by preferential flow along soil pipes, desiccation cracks and the bedrock surface. The mobile tracer fraction thus resembles the fast infiltration and subsurface flow processes which are dominating subsurface stormflow characteristics at this site.

The tracer BTCs obtained under steady-state conditions were reproduced reasonably well by a one-dimensional convection dispersion model. Despite the relatively large transport distances of the tracer experiments, the resulting Peclét numbers were low, which implies that Lagrangian transport distances for this highly dispersive medium are in the range of tens of metres. Furthermore, the steady-state BTCs offer only a limited view on the flow processes, and any lumpedprocess representation is not necessarily applicable for predicting subsurface transport under different conditions (rainfall input, soil moisture state) or along different flow paths. This conclusion is corroborated by the tracer BTCs obtained under transient natural rainfall conditions, which interestingly were closely related to rainfall and discharge dynamics. Transport paths and breakthrough velocities were strongly dependent on the application locations, the heterogeneity of rainfall and the respective spatial arrangement of flow paths.

Preferential flow and transport at the hillslope scale lead to very inefficient mixing that exacerbates and utilisation of the widely used CDE approach. Transfer functions as lumped representations of transport processes are conditional on, and thus limited to, the range of experimental conditions. The setup of a numerical model to simulate this fast responding system, which is intended for a consecutive study, will require detailed representations of subsurface structures and heterogeneities. Nevertheless, the experimental results obtained in this study demonstrates both the potential and the limitations of applied tracers for exploring site-specific characteristics of subsurface stormflow processes at the hillslope scale, and will provide an integral part of the data basis for future applications in hillslope hydrological modelling at this site.
Acknowledgements. Thanks are due to Niko Bornemann, Mareike Eichler and Erik Sommerer for their motivated assistance during field work, and to Wolfgang Peter for providing technical support. We thank Jim Freer and two anonymous reviewers for helpful comments on earlier versions of the manuscript. This work has been funded by Deutsche Forschungsgemeinschaft (DFG For 581).

\section{References}

Amoozegar, A.: A compact constant-head permeameter for measuring saturated hydraulic conductivity of the vadose zone, Soil Sci. Soc. Am. J., 53, 1356-1361, 1989.

Anderson, A. E., Weiler, M., Alila, Y., and Hudson, R. O.: Dye staining and excavation of a lateral preferential flow network, Hydrol. Earth Syst. Sci., 13, 935-944, 2009, http://www.hydrol-earth-syst-sci.net/13/935/2009/.

Binley, A., Henry-Poulter, S., and Shaw, B.: Examination of solute transport in an undisturbed soil column using electrical resistance tomography, Water Resour. Res., 32, 763-769, 1996.

Blume, T., Zehe, E., and Bronstert, A.: Investigation of runoff generation in a pristine, poorly gauged catchment in the Chilean Andes II: Qualitative and quantitative use of tracers at three spatial scales, Hydrol. Process., 22, 3676-3688, doi:10.1002/hyp.6970, 2008.

Bonell, M.: Progress in the understanding of runoff generation dynamics in forests, J. Hydrol., 150, 217-275, 1993.

Bouma, J. and Dekker, L. W.: A method for measuring the vertical and horizontal Ksat of clay soils with macropores, Soil Sci. Soc. Am. J., 45, 662-663, 1981.

Brusseau, M. L., Hu, Q., and Srivastava, R.: Using flow interruption to identify factors causing nonideal contaminant transport, J. Contam. Hydrol., 24, 205-219, 1997.

Chua, L. H. C., Robertson, A. P., Yee, W. K., Shuy, E. B., Lo, E. Y. M., Lim, T. T., and Tan, S. K.: Use of Fluorescein as a Ground Water Tracer in Brackish Water Aquifers, Ground Water, 45, 8588, 2007.

Das, B. S., Wraith, J. M., Kluitenberg, G. J., Langner, H. M., Shouse, P. J., and Inskeep, W. P.: Evaluation of mass recovery impacts on transport parameters using least-squares optimization and moment analysis, Soil Sci. Soc. Am. J., 69, 1209-1216, 2005.

Deeks, L. K., Bengough, A. G., Stutter, M. I., Young, I. M., and Zhang, X. X.: Characterisation of flow paths and saturated conductivity in a soil block in relation to chloride breakthrough, J. Hydrol., 348, 431-441, 2008.

Divine, C. E. and McDonnell, J. J.: The future of applied tracers in hydrogeology, Hydrogeol. J., 13, 255-258, 2005.

Flury, M. and Wai, N. N.: Dyes as tracers for vadose zone hydrology, Rev. Geophys., 41, 1002, doi:10.1029/2001RG000109, 2003.

Flury, M., Flühler, H., Jury, W. A., and Leuenberger, J.: Susceptibility of Soils to Preferential Flow of Water - a Field-Study, Water Resour. Res., 30, 1945-1954, 1994.

Freer, J., McDonnell, J. J., Beven, K. J., Peters, N. E., Burns, D. A., Hooper, R. P., Aulenbach, B., and Kendall, C.: The role of bedrock topography on subsurface storm flow, Water Resour. Res., 38, 1269, doi:10.1029/2001WR000872, 2002. 
Germann, P. F.: Length scales of convection-dispersion approaches to flow and tranport in porous media, J. Contam. Hydrol., 7, 3949, 1991.

Haas, C. N.: Moment analysis of tracer experiments, J. Environ. Eng.-ASCE, 122, 1121-1130, 1996.

Henderson, D. E., Reeves, A. D., Beven, K. J., and Chappell, N. A.: Flow separation in undisturbed soil using multiple anionic tracers, 2. Steady-state core-scale rainfall and return flows and determination of dispersion parameters, Hydrol. Process., 10, 14511465, 1996.

Hornberger, G. M., Beven, K. J., and Germann, P. F.: Inferences about solute transport in macroporous forest soils from time series models, Geoderma, 46, 249-262, doi:10.1016/ 0016-7061(90)90018-5, 1990.

Jensen, K. H., Destouni, G., and Sassner, M.: Advectiondispersion analysis of solute transport in undisturbed soil monoliths, Ground Water, 34, 1090-1097, 1996.

Joerin, C., Beven, K. J., Musy, A., and Talamba, D.: Study of hydrological processes by the combination of environmental tracing and hill slope measurements: application on the Haute-Mentue catchment, Hydrol. Process., 19, 3127-3145, 2005.

Jones, J. A. A. and Connelly, L. J.: A semi-distributed simulation model for natural pipeflow, J. Hydrol., 262, 28-49, 2002.

Jury, W. A.: Simulation of Solute Transport Using a TransferFunction Model, Water Resour. Res., 18, 363-368, 1982.

Jury, W. A. and Roth, K.: Transfer Functions and Solute Movement Through Soil, Birkhäuser Verlag, Basel, Switzerland, 235 pp., 1990.

Kasnavia, T., Vu, D., and Sabatini, D. A.: Fluorescent Dye and Media Properties Affecting Sorption and Tracer Selection, Ground Water, 37, 376-381, 1999.

Käss, W.: Tracing technique in geohydrology, Balkema, Rotterdam, The Netherlands, 581 pp., 1998.

Kienzler, P. M. and Naef, F.: Subsurface storm flow formation at different hillslopes and implications for the "old water paradox", Hydrol. Process., 22, 104-116, 2008a.

Kienzler, P. M. and Naef, F.: Temporal variability of subsurface stormflow formation, Hydrol. Earth Syst. Sci., 12, 257-265, $2008 b$.

Kirchner, J. W., Feng, X. H., and Neal, C.: Catchment-scale advection and dispersion as a mechanism for fractal scaling in stream tracer concentrations, J. Hydrol., 254, 82-101, 2001.

Lange, H., Lischeid, G., Hoch, R., and Hauhs, M.: Water flow paths and residence times in a small headwater catchment at Gardsjon, Sweden, during steady state storm flow conditions, Water Resour. Res., 32, 1689-1698, 1996.

Leu, C., Singer, H., Stamm, C., Müller, S. R., and Schwarzenbach, R. P.: Variability of herbicide losses from 13 fields to surface water within a small catchment after a controlled herbicide application, Environ. Sci. Technol., 38, 3835-3841, 2004.

Leu, C., Singer, H., Müller, S. R., Schwarzenbach, R. P., and Stamm, C.: Comparison of atrazine losses in three small headwater catchments, J. Environ. Qual., 34, 1873-1882, 2005.

Lindenmaier, F.: Hydrology of a large unstable hillslope at Ebnit, Vorarlberg - Identifying dominating processes and structures, Ph.D. thesis, University of Potsdam, online available at: http: //opus.kobv.de/ubp/volltexte/2008/1742/, 2008.

Lindenmaier, F., Zehe, E., Dittfurth, A., and Ihringer, J.: Process identification at a slow-moving landslide in the Vorarlberg Alps,
Hydrol. Process., 19, 1635-1651, 2005.

Luxmoore, R. J., Jardine, P. M., Wilson, G. V., Jones, J. R., and Zelazny, L. W.: Physical and chemical controls of preferred path flow through a forested hillslope, Geoderma, 46, 139-154, 1990.

McDonnell, J. J.: A Rationale for Old Water Discharge through Macropores in a Steep, Humid Catchment, Water Resour. Res., 26, 2821-2832, 1990.

McGrath, G. S., Hinz, C., and Sivapalan, M.: Modelling the impact of within-storm variability of rainfall on the loading of solutes to preferential flow pathways, Eur. J. Soil Sci., 59, 24-33, 2008.

McGuire, K. J. and McDonnell, J. J.: A review and evaluation of catchment transit time modeling, J. Hydrol., 330, 543-563, 2006.

McIntosh, J., McDonnell, J. J., and Peters, N. E.: Tracer and hydrometric study of preferential flow in large undisturbed soil cores from the Georgia Piedmont, USA, Hydrol. Process., 13, 139155, 1999.

Mikovari, A., Peter, C., and Leibundgut, C.: Investigation of preferential flow using tracer techniques, in: International Symposium on Tracer Technologies for Hydrological Systems, at the XXI General Assembly of the IUGG, Boulder, Co, USA, edited by: Leibundgut, C., 87-97, IAHS Publ. No. 229, 1995.

Mosley, M. P.: Streamflow Generation in a Forested Watershed, New Zealand, Water Resour. Res., 15, 795-806, 1979.

Noguchi, S., Tsuboyama, Y., Sidle, R. C., and Hosoda, I.: Morphological characteristics of macropores and the distribution of preferential flow pathways in a forested slope segment, Soil Sci. Soc. Am. J., 63, 1413-1423, 1999.

Omoti, U. and Wild, A.: Use of Fluorescent Dyes to Mark the Pathways of Solute Movement Through Soils Under Leaching Conditions - 1. Laboratory Experiments, Soil Sci., 128, 28-33, 1979a.

Omoti, U. and Wild, A.: Use of Fluorescent Dyes to Mark the Pathways of Solute Movement Through Soils Under Leaching Conditions - 2. Field Experiments, Soil Sci., 128, 98-104, 1979 b.

Pearce, A. J., Stewart, M. K., and Sklash, M. G.: Storm runoff generation in humid headwater catchments: 1 . Where does the water come from?, Water Resour. Res., 22, 1263-1272, 1986.

Pierson, T. C.: Soil pipes and slope stability, Q. J. Eng. Geol., 16, $1-11,1983$.

Ptak, T. and Schmid, G.: Dual-tracer transport experiments in a physically and chemically heterogeneous porous aquifer: Effective transport parameters and spatial variability, J. Hydrol., 183, 117-138, 1996.

Ptak, T., Piepenbrink, M., and Martac, E.: Tracer tests for the investigation of heterogeneous porous media and stochastic modelling of flow and transport - a review of some recent developments, J. Hydrol., 294, 122-163, 2004.

Roth, K., Jury, W. A., Flühler, H., and Attinger, W.: Transport of chloride through an unsaturated field soil, Water Resour. Res., 27, 2533-2541, 1991.

Scherrer, S. and Naef, F.: A decision scheme to indicate dominant hydrological flow processes on temperate grassland, Hydrol. Process., 17, 391-401, 2003.

Scherrer, S., Naef, F., Faeh, A. O., and Cordery, I.: Formation of runoff at the hillslope scale during intense precipitation, Hydrol. Earth Syst. Sci., 11, 907-922, 2007, http://www.hydrol-earth-syst-sci.net/11/907/2007/.

Sidle, R. C., Tsuboyama, Y., Noguchi, S., Hosoda, I., Fujieda, M., and Shimizu, T.: Stormflow generation in steep forested headwaters: a linked hydrogeomorphic paradigm, Hydrol. Process., 14, 
369-385, 2000.

Sidle, R. C., Noguchi, S., Tsuboyama, Y., and Laursen, K.: A conceptual model of preferential flow systems in forested hillslopes: evidence of self-organization, Hydrol. Process., 15, 1675-1692, 2001.

Smart, P. L. and Laidlaw, I. M. S.: Evaluation of some fluorescent dyes for water tracing, Water Resour. Res., 13, 15-33, 1977.

Sobieraj, J. A., Elsenbeer, H., and Cameron, G.: Scale dependency in spatial patterns of saturated hydraulic conductivity, Catena, 55, 49-77, 2004.

Stamm, C., Sermet, R., Leuenberger, J., Wunderli, H., Wydler, H., Flühler, H., and Gehre, M.: Multiple tracing of fast solute transport in a drained grassland soil, Geoderma, 109, 245-268, 2002.

Toride, N., Leij, F., and van Genuchten, M.: The CXTFIT code for estimating transport parameters from laboratory or field tracer experiments - Version 2.1., Research Report 137, US Salinity Laboratory, USDA, ARS, Riverside CA, 1999.

Tromp-van Meerveld, H. J. and McDonnell, J. J.: Threshold relations in subsurface stormflow: 2. The fill and spill hypothesis, Water Resour. Res., 42, W02411, doi:10.1029/2004WR003800, 2006.

Tromp-van Meerveld, H. J., Peters, N. E., and McDonnell, J. J.: Effect of bedrock permeability on subsurface stormflow and the water balance of a trenched hillslope at the Panola Mountain Research Watershed, Georgia, USA, Hydrol. Process., 21, 750-769, 2007.

Tsuboyama, Y., Sidle, R. C., Noguchi, S., and Hosoda, I.: Flow and Solute Transport Through the Soil Matrix and Macropores of a Hillslope Segment, Water Resour. Res., 30, 879-890, 1994.

Uchida, T., Kosugi, K., and Mizuyama, T.: Effects of pipeflow on hydrological process and its relation to landslide: a review of pipeflow studies in forested headwater catchments, Hydrol. Process., 15, 2151-2174, 2001.

Uchida, T., Kosugi, K., and Mizuyama, T.: Effects of pipe flow and bedrock groundwater on runoff generation in a steep headwater catchment in Ashiu, central Japan, Water Resour. Res., 38, 1119, doi:10.1029/2001WR000261, 2002.

Uchida, T., Asano, Y., Mizuyama, T., and McDonnell, J. J.: Role of upslope soil pore pressure on lateral subsurface storm flow dynamics, Water Resour. Res., 40, W12401, doi:10.1029/ 2003WR002139, 2004.

Uchida, T., McDonnell, J. J., and Asano, Y.: Functional intercomparison of hillslopes and small catchments by examining water source, flowpath and mean residence time, J. Hydrol., 327, 627642, 2006.
Uhlenbrook, S., Frey, M., Leibundgut, C., and Maloszewski, P. Hydrograph separations in a mesoscale mountainous basin at event and seasonal timescales, Water Resour. Res., 38, 1096, doi: 10.1029/2001WR000938, 2002.

van Genuchten, M. and Alves, W.: Analytical solutions of the one-dimensional convective-dispersive solute transport equation, Technical Bulletin 1661, USDA, ARS, Washington, DC, 1982.

Vanderborght, J., Timmerman, A., and Feyen, J.: Solute Transport for Steady-State and Transient Flow in Soils with and without Macropores, Soil Sci. Soc. Am. J., 64, 1305-1317, 2000.

Weiler, M. and McDonnell, J. J.: Conceptualizing lateral preferential flow and flow networks and simulating the effects on gauged and ungauged hillslopes, Water Resour. Res., 43, W03403, doi: 10.1029/2006WR004867, 2007.

Weiler, M. and Naef, F.: An experimental tracer study of the role of macropores in infiltration in grassland soils, Hydrol. Process., 17, 477-493, 2003.

Weiler, M., McDonnell, J. J., Tromp-van Meerveld, I., and Uchida, T.: Subsurface Stormflow, in: Encyclopedia of Hydrological Sciences, edited by: Anderson, M. G. and McDonnell, J. J., Wiley \& Sons, doi:10.1002/0470848944.hsa119, 2006.

Wienhöfer, J., Lindenmaier, F., Ihringer, J., and Zehe, E.: Characterization of soil hydraulic properties on a creeping alpine slope, in: Hydrology in Mountain Regions: Observations, Processes and Dynamics (Proceedings of Symposium HS1003 at IUGG2007, Perugia, Italy, July 2007), edited by: Marks, D., IAHS Publ. No. 326, 2009.

Williams, A. G., Dowd, J. F., and Meyles, E. W.: A new interpretation of kinematic stormflow generation, Hydrol. Process., 16 , 2791-2803, 2002.

Wilson, G. V., Jardine, P. M., Luxmoore, R. J., Zelazny, L. W., Lietzke, D. A., and Todd, D. E.: Hydrogeochemical processes controlling subsurface transport from an upper subcatchment of Walker Branch watershed during storm events. 1. Hydrologic transport processes, J. Hydrol., 123, 297-316, 1991.

Zehe, E. and Flühler, H.: Slope scale variation of flow patterns in soil profiles, J. Hydrol., 247, 116-132, 2001a.

Zehe, E. and Flühler, H.: Preferential transport of isoproturon at a plot scale and a field scale tile-drained site, J. Hydrol., 247, 100-115, 2001b. 